\title{
Difference between the Lagrangian trajectories and Eulerian residual velocity fields in the southwestern Yellow Sea
}

\author{
Bin Wang • Naoki Hirose • \\ Jae-Hong Moon • Dongliang Yuan
}

Received: 31 August 2012 / Accepted: 12 March 2013 /Published online: 6 April 2013

(C) The Author(s) 2013. This article is published with open access at Springerlink.com

\begin{abstract}
The responses to tidal and/or wind forces of Lagrangian trajectories and Eulerian residual velocity in the southwestern Yellow Sea are investigated using a highresolution circulation model. The simulated tidal harmonic constants agree well with observations and existing studies. The numerical experiment reproduces the long-range southeastward Eulerian residual current over the sloping bottom around the Yangtze Bank also shown in previous studies. However, the modeled drifters deployed at the northeastern flank of the Yangtze Bank in the simulation move northeastward, crossing over this strong southeastward Eulerian residual current rather than following it. Additional sensitivity experiments reveal that the influence of the Eulerian tidal residual currents on Lagrangian trajectories is relatively
\end{abstract}

Responsible Editor: Hidenori Aiki

This article is part of the Topical Collection on the 4th International Workshop on Modelling the Ocean in Yokohama, Japan 21-24 May 2012

B. Wang $(\triangle) \cdot$ N. Hirose

Department of Earth System Science and Technology,

Interdisciplinary Graduate School of Engineering Science,

Kyushu University, Kasuga, Japan

e-mail: wangbin@riam.kyushu-u.ac.jp

N. Hirose

Research Institute for Applied Mechanics, Kyushu University,

Kasuga, Japan

J.-H. Moon

Jet Propulsion Laboratory, California Institute of Technology,

California, USA

D. Yuan

Key Laboratory of Ocean Circulation and Wave, Chinese

Academy of Sciences, Qingdao, China

D. Yuan

Institute of Oceanology, Chinese Academy of Sciences, Qingdao, China weaker than that of the wind driven currents. This result is consistent with the northeastward movement of ARGOS surface drifters actually released in the southwestern Yellow Sea. Further experiments suggest that the quadratic nature of the bottom friction is the crucial factor, in the southwestern Yellow Sea, for the weaker influence of the Eulerian tidal residual currents on the Lagrangian trajectories. This study demonstrates that the Lagrangian trajectories do not follow the Eulerian residual velocity fields in the shallow coastal regions of the southwestern Yellow Sea.

Keywords Eulerian residual velocity $\cdot$ Eulerian tidal residual current · Yellow Sea · Lagrangian drifter · Bottom friction parameterization

\section{Introduction}

The Yellow Sea is a semi-enclosed embayment located between the Chinese mainland and the Korean Peninsula. The bottom of the southwestern Yellow Sea is varied and is quite shallow, especially at the Yangtze Bank where the water depth is generally less than $20 \mathrm{~m}$ (Fig. 1). The basin geometry, varied topography and shallow water cause that the circulations and tides in this area are extremely complex and difficult to model and predict. Furthermore, due to the limited direct current measurements that have been made until now, the understanding of the circulation in the southwestern Yellow Sea is still primitive.

The strong tides and tidal currents in the East China Sea and Yellow Sea have been well known to investigators from field observation data (Ogura 1933; Nishida 1980; Larsen et al. 1985; Fang 1986), satellite altimetric sea level data (Yanagi et al. 1997), and a series of numerical models (An 1977; Shen 1980; Choi 1980, 1984, 1990; Yanagi and Inoue 1994; Zhao et al. 1993; Ye and Mei 1995; Kang et al. 1998; 


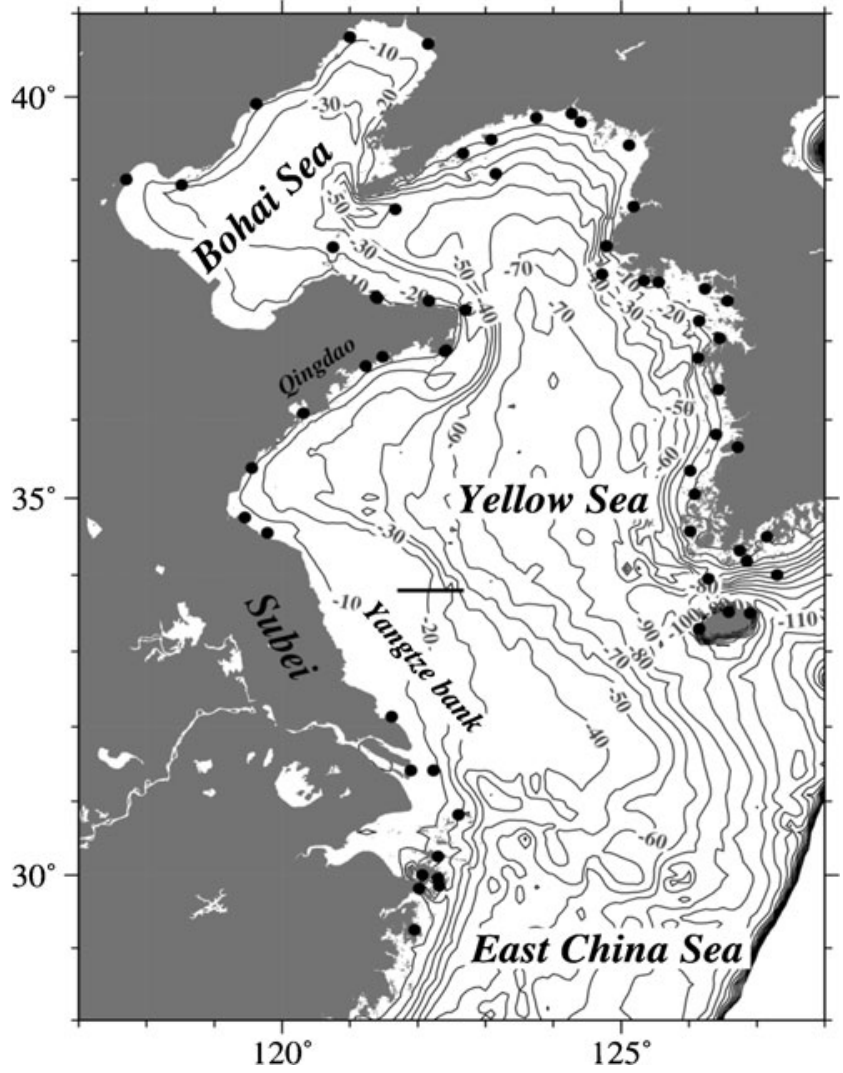

Fig. 1 Model domain and topography. The thick solid line shows the initial location of artificial drifters (the contour interval is $10 \mathrm{~m}$ ). Black dots are the locations of the tidal observation stations

Kang et al. 2002; Moon et al. 2009). According to the existing results, the Eulerian tidal residual current forms a basin-scale cyclonic circulation in the central of the Yellow Sea, while it flows northward along the Subei coast as a part of an anticyclonic gyre. It has been suggested that the large tidal amplitudes over the sloping bottom around the Yangtze Bank, which lies between the basin scale cyclonic circulation and the anticyclonic gyre, produce strong southeastward residual currents. In particular, the weak monsoon and surface heating allow strong thermal stratification in summer leading to a significant sub-surface intensification of this southeastward residual current (Lee and Beardsley 1999), which could play an important role in the regional circulation. Conceptual models (Lie 1986; Hu et al. 1991; $\mathrm{Hu}$ 1994), drifter tracking observations (Beardsley et al. 1992), and numerical studies (Yanagi and Takahashi 1993; Takahashi and Yanagi 1995; Tang et al. 2000; Xu et al. 2002) have revealed a cyclonic baroclinic frontal circulation associated with the strong thermal fronts in the central part of the Yellow Sea, roughly along the 40-50-m isobaths. The southeastward Eulerian tidal residual current is thought to strengthen the basin-scale cyclonic circulation in the central part of the Yellow Sea in summer time (Xia et al. 2006).
Recently, Yuan et al. (2008) discovered that the Subei coast current actually flowed northward in summer time in response to the southerly wind forcing. This northward flow was confirmed by the satellite tracking of algal patches movements during the green tide event (Ulva prolifera bloom) off Qingdao in the summer of $2008(\mathrm{Hu}$ and $\mathrm{He}$ 2008; Qiao et al. 2008; Hu et al. 2010). Furthermore, the trajectories of ARGOS surface drifters released in the southwestern Yellow Sea in the summer of 2009 have confirmed this northward Subei coast current (Li 2010). Instead of following the southeastward Eulerian residual current, the ARGOS surface drifters flowed northeastward and meandered through it (Fig. 2).

The straightforward definition of the Eulerian residual current is the averaged velocities at a fixed location over multiple tidal periods (Abbott 1960). Comparing with the Lagrangian framework, the Eulerian residual velocity is more widely used to explain the mass transport in shallow seas. However, the Eulerian residual currents do not always represent the net movement of the water parcel. As was first theoretically pointed out by Longuet-Higgins (1969), the velocity of the water parcel is controlled not only by the mean velocity at that point (Eulerian residual velocity) but also by the Stokes drift velocity. There are extra-dispersion terms in the inter-tidal transport equation (Fischer et al. 1979). In short, the Lagrangian trajectories do not necessarily follow the Eulerian residual velocity field in the presence

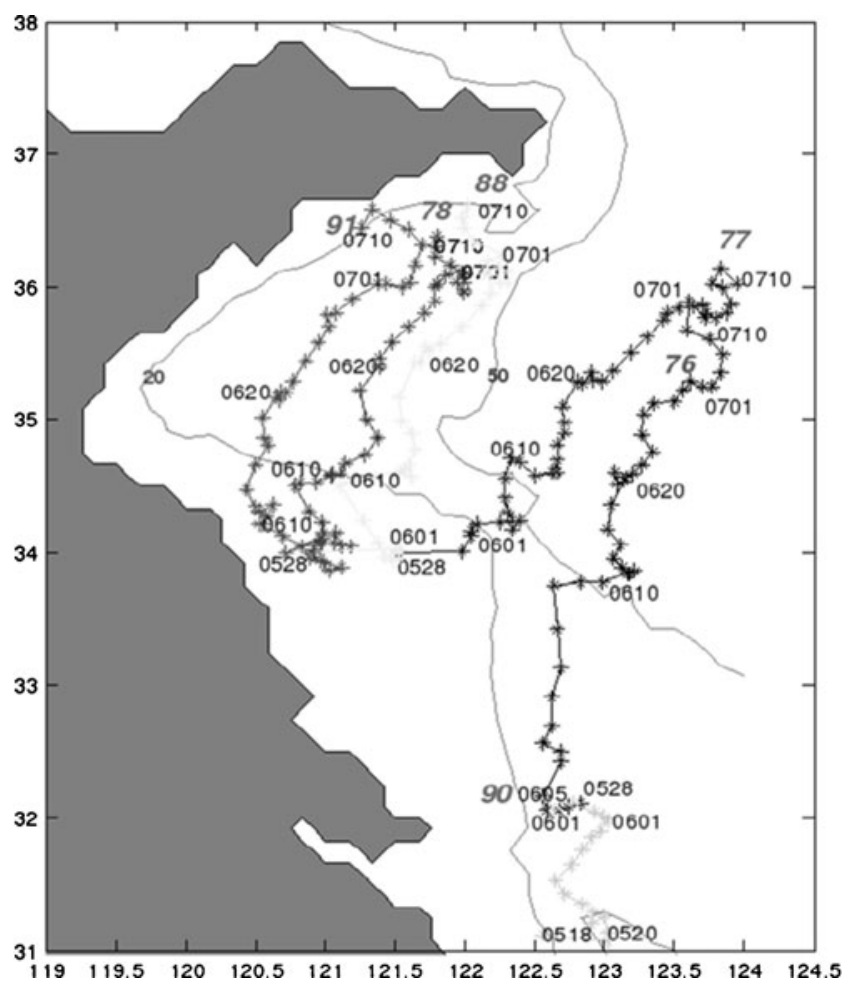

Fig. 2 The trajectories of surface ARGOS drifters from Li (2010) in the summer of 2009 (Fig. 3.2 in that paper) 
of oscillatory tidal motion. The previous studies and the behavior of the ARGOS surface drifters suggest that the Eulerian residual current flows southeastward over the sloping bottom around the Yangtze Bank, while the Lagrangian drifters extend northeastward, which could be a particular example of the above principle.

Previous models have demonstrated, both quantitatively and qualitatively, the differences between the tidal-induced only Lagrangian and the Eulerian residual velocities in an idealized narrow bay (Ianniello 1977; Jiang and Feng 2011) and Bohai Sea (Breton and Salomon 1995; Wei et al. 2004). Only a few researches (Feng 1990; Delhez 1996) have directly pointed out the accuracy of the Lagrangian residual current in representing the long-term transport in the light of the tides, atmospheric forcing and density-driven currents. In the present study, we have used a numerical model to investigate the Lagrangian trajectories and the Eulerian residual velocity in response to tidal and wind forces in the southwestern Yellow Sea. This model could have practical applications, such as predicting green-tide events, which have occurred frequently on the beach of Qingdao city during recent summers. The data and model are described in the following section. The model validation and results of the numerical experiments are presented in Section 3. In Section 4, we consider the effects of using synoptic winds instead of climatological wind stress in the simulations. The last section outlines our conclusions.

\section{Data and model}

The Princeton Ocean Model (POM) is applied to study the difference between the Lagrangian trajectories and the Eulerian residual velocity in the southwestern Yellow Sea. The model domain and topography are shown in Fig. 1. The model covers the domain of $\left(28^{\circ} \mathrm{N}-41^{\circ} \mathrm{N}, 117^{\circ} \mathrm{E}-128^{\circ} \mathrm{E}\right)$, with a horizontal resolution of $1 / 12^{\circ} \times 1 / 12^{\circ}$. There are 16 vertical levels with sigma coordinates $0.000,-0.003,-0$. $006,-0.013,-0.025,-0.050,-0.100,-0.200,-0.300,-0$. $400,-0.500,-0.600,-0.700,-0.800,-0.900$, and -1.00 from surface to bottom. The topography is averaged from $1^{\prime} \times 1^{\prime}$ depth data of the Coastal and Ocean Dynamics Studies Laboratory of Sungkyunkwan University (Choi et al. 2002). Two modifications, setting the maximum water depth to $140 \mathrm{~m}$ and the minimum water depth to $10 \mathrm{~m}$, are made to the original topography data to relax the CFL condition and to reduce possible errors in the finitedifference of the baroclinic pressure gradient over steep topography with a vertical sigma coordinate grid (Haney 1991; Chen et al. 1995a, b).

Tidal forces including $\mathrm{M}_{2}, \mathrm{~S}_{2}, \mathrm{~K}_{1}$, and $\mathrm{O}_{1}$ are considered on the open boundary by using a fixed radiation condition for the depth-averaged velocity. The tidal amplitudes and phases are taken from the global $0.25^{\circ} \times 0.25^{\circ} \mathrm{TPX} 0.6$ tide model (Gary et al. 1994). The tidal forcing is ramped up to full amplitude within the first two tidal periods to minimize starting transients. The climatological monthly wind stress fields from the Japanese 25-year re-analysis (JRA-25) dataset are interpolated to force the numerical model. The model is integrated for two months from May to June because that is when the southerly wind stresses as well as the wind effects are weak. The initial and boundary conditions are determined from a $1 / 4^{\circ} \times 1 / 5^{\circ}$ Western North Pacific Ocean Model (Hirose 2011). The sea surface temperature and salinity are relaxed to the climatology obtained from the same large-scale model instead of surface heat and salinity flux conditions. The tangential components of velocity, temperature, and salinity at the open boundaries satisfy zero-gradient conditions.

Numerical experiments performed in this study are shown in Table 1 . The first experiment $T_{\mathrm{Q}}$ is conducted using only tidal forcing, whereas $W_{\mathrm{Q}}$ uses only climatological wind forcing. The third experiment called $\mathrm{WT}_{\mathrm{Q}}$ includes both tidal forcing and climatological wind forcing. In all the cases, the superscript Q means that the bottom friction term is given by the nonlinear quadratic parameterization:

$$
\vec{F}_{\mathrm{Q}}=-C_{D}|\vec{u}| \vec{u}
$$

where $\vec{u}$ is the near bottom velocity vector. The drag coefficient $C_{\mathrm{D}}$ is 0.001 in the Bohai Sea, while it is 0.0016 in the other areas (Wan et al. 1998). The comparison of these three numerical experimental results will indicate the primary driving force of Lagrangian currents in the southwestern Yellow Sea. As the bottom friction has strong effects on the regional circulation (Jiang and Feng 2011), additional experiments $T_{\mathrm{L}}$, $W_{\mathrm{L}}$, and $\mathrm{WT}_{\mathrm{L}}$ are designed to check the effects of the bottom friction. The superscript L means that the linear bottom friction scheme

$\vec{F}_{L}=-\Gamma_{L} \vec{u}$

is used. Apart from the bottom friction scheme, the experiments $T_{\mathrm{L}}, W_{\mathrm{L}}$, and $\mathrm{WT}_{\mathrm{L}}$ assume the same conditions as $T_{\mathrm{Q}}$, $W_{\mathrm{Q}}$, and $\mathrm{WT}_{\mathrm{Q}}$, respectively. After some sensitivity experiments to match the nonlinear cases in terms of kinetic energy, we chose the linear drag coefficients $\Gamma_{\mathrm{L}}$ to be 0.0005 in the Bohai Sea and 0.0008 in the other areas.

The movement of the upper layer water parcel in the southwestern Yellow Sea is studied by modeling the trajectories of the modeled drifters, which are deemed to be Lagrangian tracers. The trajectories are calculated by the fourth-order Runge-Kutta scheme. A hundred modeled drifters are released at a depth of $15 \mathrm{~m}$ along the $33.80^{\circ} \mathrm{N}$ section (Fig. 1). In each experiment, the positions of the drifters are calculated every 2 computational hours after the model has been running for 15 simulated days. 
Table 1 The final mean meridional displacement of the artificial drifters and the area-averaged magnitude of the bottom momentum flux in each experiment

\begin{tabular}{|c|c|c|c|c|}
\hline Experiment & Forcing & Bottom friction & $\begin{array}{l}\text { Final mean meridional } \\
\text { displacement }(\mathrm{km})\end{array}$ & $\begin{array}{l}\text { Bottom momentum } \\
\text { flux }\left(\times 10^{-3} \mathrm{~N} / \mathrm{m}^{2}\right)\end{array}$ \\
\hline$T_{\mathrm{Q}}$ & Only tidal forcing & \multirow[t]{4}{*}{ Quadratic } & -59.28 & 8.10 \\
\hline$W_{\mathrm{Q}}$ & Only climatological wind & & +111.78 & 1.70 \\
\hline $\mathrm{WT}_{\mathrm{Q}}$ & Both tidal and climatological wind & & +97.33 & 12.7 \\
\hline Linear combination of $W_{\mathrm{Q}}$ and $T_{\mathrm{Q}}$ & & & +52.52 & \\
\hline$T_{\mathrm{L}}$ & Only tidal forcing & \multirow[t]{4}{*}{ Linear } & -48.02 & 5.80 \\
\hline$W_{\mathrm{L}}$ & Only climatological wind & & +139.73 & 8.60 \\
\hline $\mathrm{WT}_{\mathrm{L}}$ & Both tidal and climatological wind & & +98.85 & 12.3 \\
\hline Linear combination of $W_{\mathrm{L}}$ and $T_{\mathrm{L}}$ & & & +92.30 & \\
\hline
\end{tabular}

\section{Results}

\subsection{Water mass distribution}

The simulated temperature structures along the vertical sections at $33^{\circ} \mathrm{N}$ and $35^{\circ} \mathrm{N}$ in June (Fig. 3) are compared with the Hydrobase 2 climatological monthly mean data. Roughly, the basic features of the summer stratification and water mass distributions are represented well by the baseline experiment $\mathrm{WT}_{\mathrm{Q}}$, suggesting that the simulated circulation reproduces the basic characteristics of the summer circulation in this region.

Both the simulated and observed temperatures are vertically uniform at the coastal area of the $33^{\circ} \mathrm{N}$ section (Fig. $3 a)$, indicating that vertical mixing is strong in this shallow area due to tidal motion (Zhao et al. 1994; Xia et al. 2006). In the central Yellow Sea, a vertical temperature gradient starts to form, characterizing the seasonal thermocline,
Fig. 3 The simulated vertical temperature distributions along the $33^{\circ} \mathrm{N}$ and $35^{\circ} \mathrm{N}$ sections
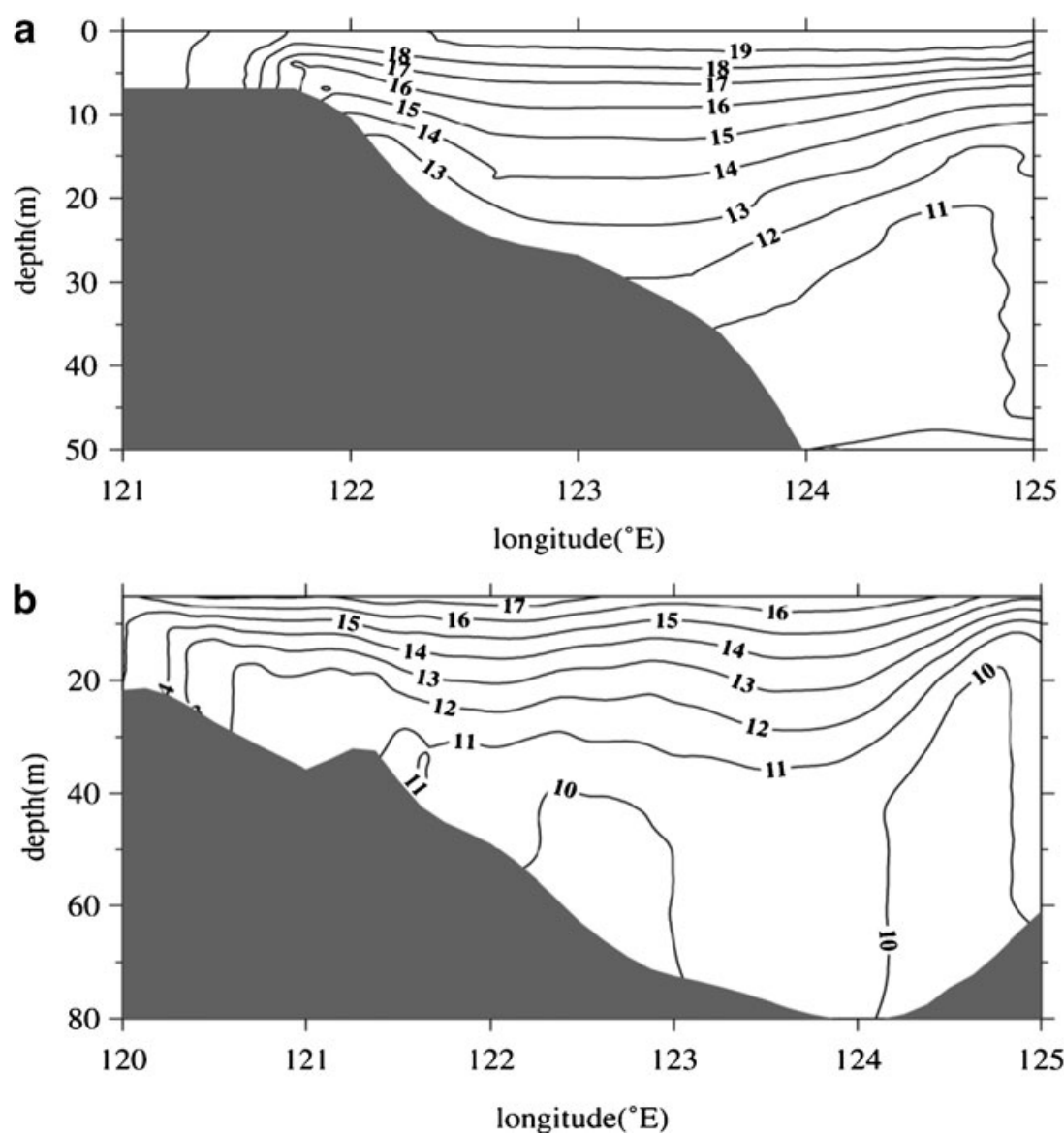
separating the water column into upper and lower layers. The upper part of the seasonal thermocline is elevated toward the sea surface while the lower part of it forms a strong front at a depth of roughly $15-20 \mathrm{~m}$.

Along the vertical section of $35^{\circ} \mathrm{N}$ (Fig. 3b), the so-called western core of the Yellow Sea Cold Water Mass is identified at a depth of 40-50 m over the slope on the western flank of the Yellow Sea trough. The intensity of the cold core is weaker than the individual observation because the simulated temperature is driven by the climatological forcing.

The pattern of the isohaline and the low salinity tongue of the Yangtze River diluted water also generally agree with observations (not shown here). All of the characters, including the thermocline and the position of the surface and subsurface water masses, are simulated well by the experiment $\mathrm{WT}_{\mathrm{Q}}$, implying that the present model has captured the essential dynamics of the current systems.

\subsection{Verification of the simulated tides}

To verify the simulated tides, only tidal forcing with homogenous water are tested in the model at first, and the temperature and salinity are set to $21{ }^{\circ} \mathrm{C}$ and $33.5 \mathrm{PSU}$, respectively. In this case, the model approaches steady state after about 5 days. After 15 days, harmonic constants are obtained by harmonic analysis. The co-tidal charts of the $\mathrm{M}_{2}, \mathrm{~S}_{2}, \mathrm{~K}_{1}$, and $\mathrm{O}_{1}$ tides generated from the model are shown in Fig. 4. These structures basically agree with the previous studies (Fang 1986; Yanagi et al. 1997; Guo and Yanagi 1998; Kang et al. 1998; Lee and Beardsley 1999; Bao et al. 2000; Fang et al. 2004). All of the semi-diurnal amphidromic points $\left(\mathrm{M}_{2}\right.$ and $\mathrm{S}_{2}$ tides $)$ and the diurnal amphidromic points $\left(\mathrm{K}_{1}\right.$ and $\mathrm{O}_{1}$ tides) in the southwestern Yellow Sea are reproduced successfully.

Forasmuch as the limitation of tidal observations, only $\mathrm{M}_{2}$ tidal harmonic constants from the model are compared with observed values of 63 sites as shown in Fig. 1. The observed data comes from Wan et al. (1998) and Zhang et al. (2005), and the model values are used after interpolation. The standard deviations between the simulated and observed $\mathrm{M}_{2}$ tidal amplitude and phase for all sites are 9 . $3 \mathrm{~cm}$ and $12.0^{\circ}$ (Fig. 5). The results show that the simulated $\mathrm{M}_{2}$ tide agrees the observations well. The results with climatological stratification (not shown here) are essentially the same as those with homogenous water.

\subsection{Eulerian residual velocity fields}

The simulated Eulerian tidal residual current at $15 \mathrm{~m}$ during June in $T_{\mathrm{Q}}$ (Fig. 6a) shows a basin-scale cyclonic circulation in the Yellow Sea. The result is similar to those of existing studies (Zhao et al. 1993; Lee and Beardsley 1999; Xia et al. 2006). Three obvious characteristics of the Eulerian tidal residual current have been reproduced. The first feature is the strong northward current around the southwest of Korea with a maximum speed of $10 \mathrm{~cm} / \mathrm{s}$. The second feature is the northward flow along the Subei coast (water depth less than $15 \mathrm{~m}$ cannot be illustrated in Fig. 6a), forming an anticyclonic gyre in the area. The third feature is the strong longrange southeastward current with a speed of $\sim 5 \mathrm{~cm} / \mathrm{s}$ over the sloping bottom around the Yangtze Bank, between the basin-scale cyclonic circulation and the anticyclonic gyre. Generally, the tides and tidal currents produced by the model agree well with previous studies.

By including wind forcing, a more realistic circulation is generated in experiment $\mathrm{WT}_{\mathrm{Q}}$. As shown in Fig. $6 \mathrm{~b}$, the circulation at a depth of $15 \mathrm{~m}$ in June is a cyclonic circulation that encompasses the entire deep basin. Along the Korean coast, the northward flow is strong; on the other hand, in the western and central parts of the Yellow Sea, the current flows southward and is much broader and weaker. In particular, along the Subei coast, the northward current is enhanced by tidal rectification (cannot be presented in Fig. $6 b)$. With the strong southeastward current over the sloping bottom around the Yangtze Bank, an anticyclonic gyre is formed next to the western limb of the cyclonic current. This result is similar to the model result of Naimie et al. (2001) and the analysis of observations in Liu (2006). The realistic features of the present model allow us to study the dynamics of the Lagrangian trajectories in the southwestern Yellow Sea.

\subsection{Lagrangian trajectories}

The Lagrangian phenomena are studied by using the trajectories of modeled drifters. Table 1 shows the mean meridional displacement of the modeled drifter movements after 45 days in each experiment. A positive value means northward movement whereas a negative value means southward movement. It should be pointed out that the thermohaline conditions and wind stress are based on climatological fields. The simulated trajectories of the modeled drifters represent a climatological Lagrangian circulation field while the observations are in the summer of a particular year. Therefore, more attention should be paid to the differences between experimental results instead of being concerned with the accurate reproduction of observed trajectories.

The modeled drifters in $\mathrm{T}_{\mathrm{Q}}$ (only tidal forcing), released at the northeastern flank of the Yangtze Bank, flow southeastward at high speed (Fig. 7a). The other drifters released at the shallow western area flow northward at a lower speed. The mean meridional displacement of all the modeled drifters is about $-59.28 \mathrm{~km}$ (Table 1), which is distinct from the mean meridional displacement of $-73.24 \mathrm{~km}$ for 
Fig. 4 Co-tidal charts simulated with homogeneous water. Solid and dashed lines show the distributions of amplitude (in meters) and phase lag (in degrees and referred to $\left.120^{\circ} \mathrm{E}\right)$, respectively
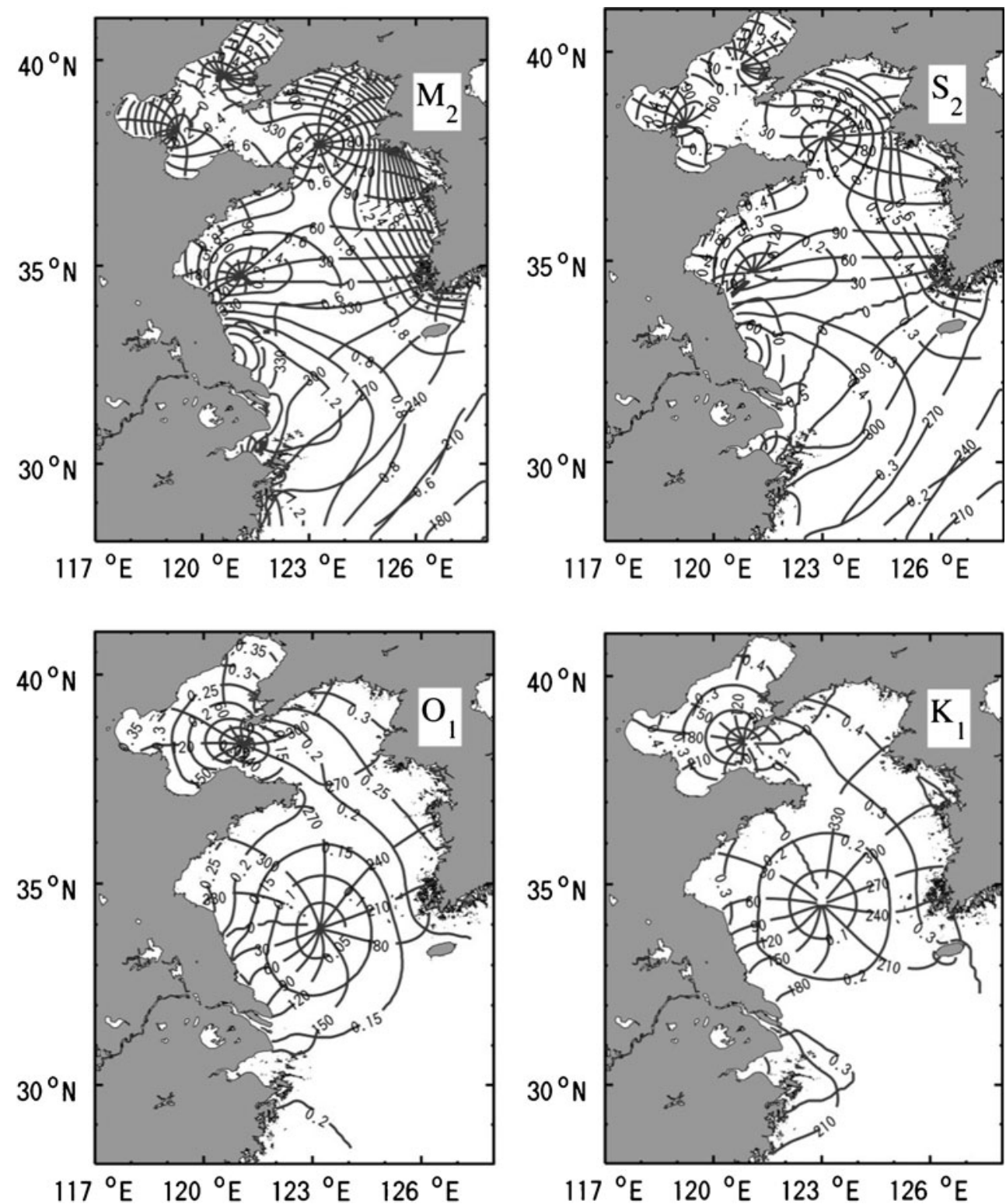

trajectories that are directly driven by the Eulerian tidal residual current (not shown here). The dissimilarity between the two sets of trajectories indicates that the Lagrangian and the Eulerian residual velocities are different, in agreement with previous studies (Longuet-Higgins 1969; Ianniello 1977; Jiang and Feng 2011).
Fig. 5 Comparison between the observed and simulated harmonic constants of the $\mathrm{M}_{2}$ tide $\mathbf{a}$ amplitude and $\mathbf{b}$ phase. Station locations are shown with black dots in Fig. 1
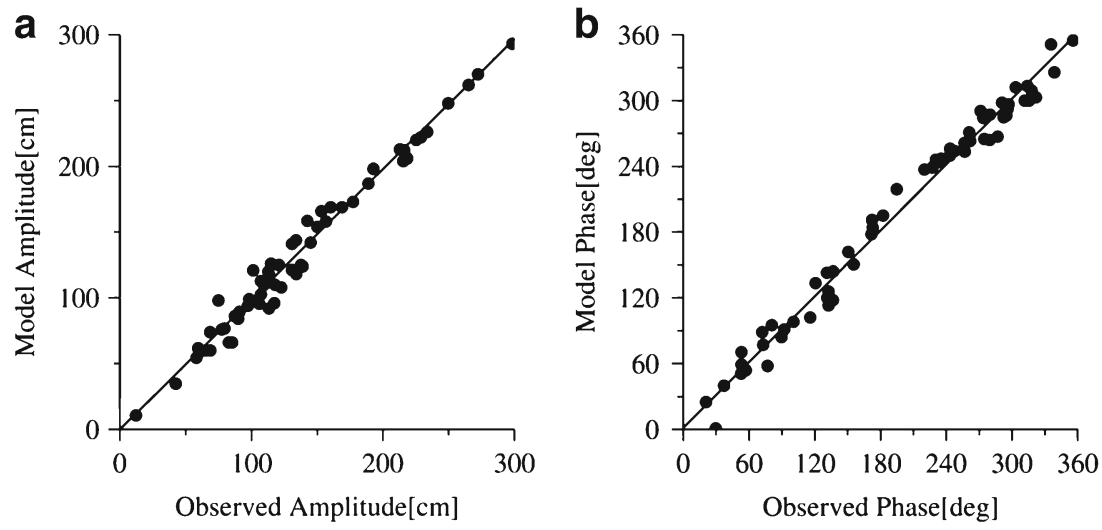
Fig. 6 a The simulated

Eulerian tidal residual currents

in $T_{\mathrm{Q}}$ and $\mathbf{b}$ the simulated

circulation in $\mathrm{WT}_{\mathrm{Q}}$ at a depth of

$15 \mathrm{~m}$ during June
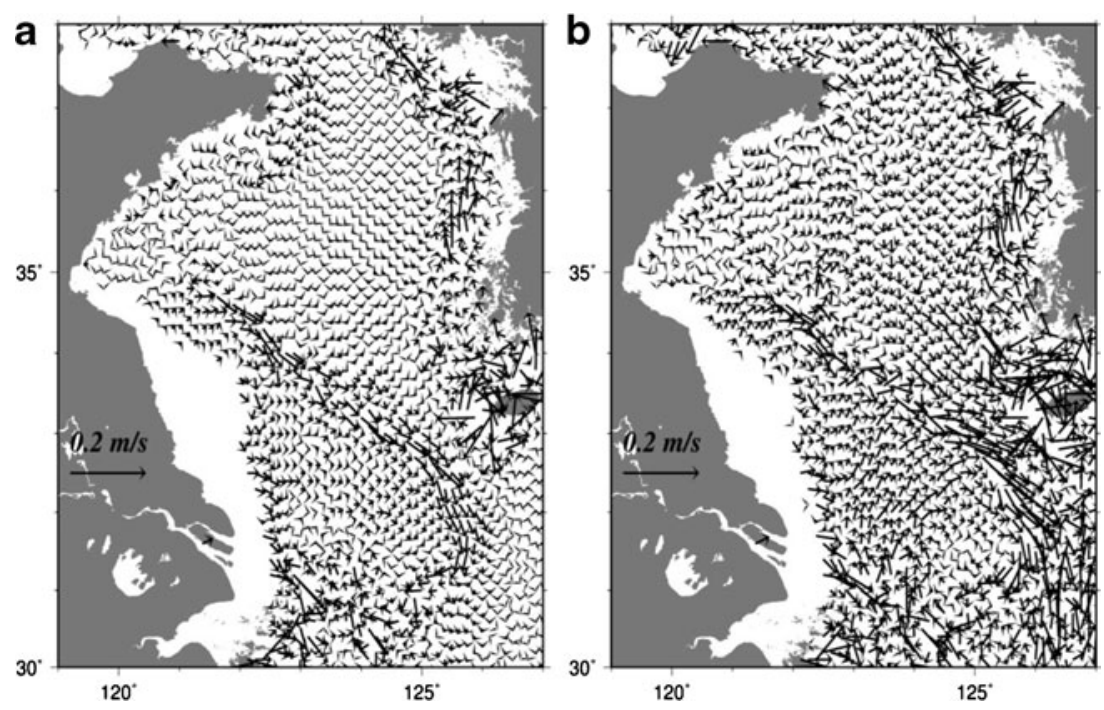

In comparison, in experiment $W_{\mathrm{Q}}$ (only climatological wind forcing) almost all these modeled drifters released at the northeastern flank of Yangtze Bank flow northeastward (Fig. 7b). The mean meridional displacement of these modeled drifters exceeds $+110 \mathrm{~km}$ (Table 1$)$.

In experiment $\mathrm{WT}_{\mathrm{Q}}$ (including both tidal and climatological wind forcing), the modeled drifters move in the similar directions as in $W_{\mathrm{Q}}$. We especially noticed a difference for the modeled drifters deployed at the northeastern flank of Yangtze Bank: these modeled drifters do not flow directly northeast but begin by moving southeast due to the effects of the strong long-range southeastward Eulerian residual current over the sloping bottom around the Yangtze Bank, as illustrated in the small box of Fig. 7c. However, the
Fig. 7 The trajectories of the artificial drifters plotted with 2.5-day interval $\mathbf{a}$ in $T_{\mathrm{Q}}$, $\mathbf{b}$ in $W_{\mathrm{Q}}, \mathbf{c}$ in $\mathrm{WT}_{\mathrm{Q}}$, with 1-day interval in the small box area, and $\mathbf{d}$ the linear combination of $W_{\mathrm{Q}}$ and $T_{\mathrm{Q}}$. The square indicates the final center of gravity of the drifters 45 days after release
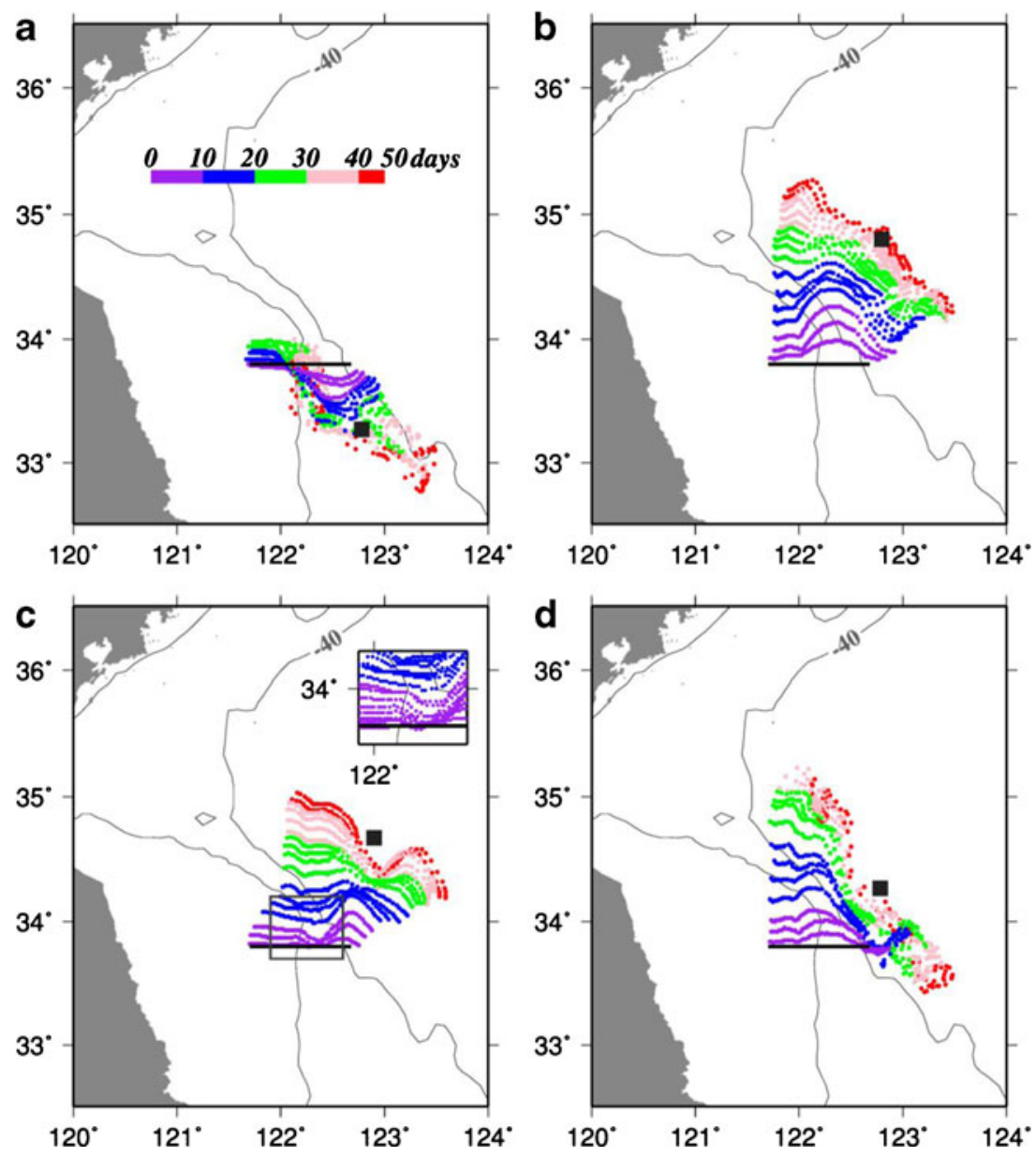
drifters easily drop out of the Eulerian residual current and move further northeastward. This indicates that the Stokes drift velocity of tidal motion is comparable in magnitude to the Lagrangian residual velocity, and eclipses the Eulerian residual velocity. The center of gravity of the modeled drifters moves northward by about $97.33 \mathrm{~km}$ from the initial latitude (Fig. 7c). The pattern of these trajectories corresponds with observations of the ARGOS surface drifters released in the southwestern Yellow Sea in the summer season of 2009 (Li 2010).

To exam the effects of wind and tide on the Lagrangian trajectories respectively, the simple average of the velocity field snapshots of $W_{\mathrm{Q}}$ and $T_{\mathrm{Q}}$ are calculated. The simple linear combination of $\mathrm{W}_{\mathrm{Q}}$ and $\mathrm{T}_{\mathrm{Q}}$ (Fig. 7d) results in a mean meridional displacement of only $+52.52 \mathrm{~km}$ (Table 1 ), which is much less than that in $\mathrm{WT}_{\mathrm{Q}}$. The tidal effect in $\mathrm{WT}_{\mathrm{Q}}$ is obviously weaker than what is expected from the linear combination. Thus, the wind stress is the dominant factor determining the Lagrangian trajectories in the southwestern Yellow Sea in summer, which could explain the transport of large numbers of green tide patches from Subei to Qingdao during recent summers.

To further understand the dynamics of these Lagrangian phenomena, the effect of bottom friction has been examined by considering the linear bottom friction scheme. $T_{\mathrm{L}}, W_{\mathrm{L}}$, and $\mathrm{WT}_{\mathrm{L}}$ have the same conditions as $T_{\mathrm{Q}}, W_{\mathrm{Q}}$, and $\mathrm{WT}_{\mathrm{Q}}$, respectively, except for the use of the linear bottom friction scheme. As shown in Fig. 8a, the results of $\mathrm{WT}_{\mathrm{L}}$ resemble those of $\mathrm{WT}_{\mathrm{Q}}$. The mean meridional displacement of the modeled drifters in $\mathrm{WT}_{\mathrm{L}}$ is about $+98.85 \mathrm{~km}$ (Table 1). In contrast, the linear combination of $W_{\mathrm{L}}$ and $T_{\mathrm{L}}$ (Fig. 8b) results in a mean meridional displacement of $+92.30 \mathrm{~km}$ (Table 1), which is relatively similar to $\mathrm{WT}_{\mathrm{L}}$, in contrast with the nonlinear cases. These results suggest that, in this region, the Lagrangian trajectories can be simply determined by linear dynamics without a quadratic friction term. In other words, the nonlinearity of the bottom friction plays an important role for the weaker influence of the tidal residual currents on Lagrangian trajectories in the southwestern Yellow Sea.

In general, bottom friction is an important sink of momentum and energy in the ocean, especially for shallow areas. The bottom momentum fluxes (hereafter BMFs) in POM are represented by

$\rho \times(\langle w u(-1)\rangle,\langle w v(-1)\rangle)=-\rho \times C_{D}|\vec{u}| \vec{u}$

where $\vec{u}$ and $C_{\mathrm{D}}$ have same meanings as in Eq. (1). The density of seawater $\rho$ is $1.025 \mathrm{~kg} / \mathrm{m}^{3}$. In the linear bottom friction parameterization approach mentioned above (Eq. (2)), the BMFs are

$\rho \times(\langle w u(-1)\rangle,\langle w v(-1)\rangle)=-\rho \times{ }_{L} \vec{u}$

Equations (3) and (4) are similar if we assume that $\Gamma_{\mathrm{L}}=$ $C_{\mathrm{D}} U$, where $U$ is the typical friction velocity. The difference between the two expressions is that $U$ is a constant $(0.5 \mathrm{~m} / \mathrm{s})$, whereas $\vec{u}$ is time-dependent and space-dependent.

The magnitudes of area-averaged BMFs are shown in Table 1. In accordance with the results described above, the BMFs of $\mathrm{WT}_{\mathrm{L}}$ and $\mathrm{WT}_{\mathrm{Q}}$ are very similar $(12.3 \times$ $10^{-3} \mathrm{~N} / \mathrm{m}^{2}$ and $12.7 \times 10^{-3} \mathrm{~N} / \mathrm{m}^{2}$, respectively) which means $\mathrm{WT}_{\mathrm{L}}$ can reproduce $\mathrm{WT}_{\mathrm{Q}}$ by choosing the appropriate value of $U$. However, the BMF in $T_{\mathrm{L}}\left(5.8 \times 10^{-3} \mathrm{~N} / \mathrm{m}^{2}\right)$ is $28.40 \%$ weaker than that of $\mathrm{T}_{\mathrm{Q}}\left(8.1 \times 10^{-3} \mathrm{~N} / \mathrm{m}^{2}\right)$ in the shallow area, whereas it is considerably enhanced in $W_{\mathrm{L}}\left(8.6 \times 10^{-3} \mathrm{~N} / \mathrm{m}^{2}\right)$ in contrast to that of $W_{\mathrm{Q}}\left(1.7 \times 10^{-3} \mathrm{~N} / \mathrm{m}^{2}\right)$.

In the southwestern Yellow Sea, the tidal currents are usually stronger than the typical friction velocity $(0.5 \mathrm{~m} / \mathrm{s})$. Conversely, the wind-driven currents in this area are normally weaker than $0.5 \mathrm{~m} / \mathrm{s}$, meaning that the BMFs of wind effects given by the quadratic relation are weaker than those given by the linear relation. This indicates that the quadratic bottom topography shear leads to strong steering effects on the regional circulation in summer. Thus, the larger BMFs in the experiment $T_{\mathrm{Q}}$ utilizing the quadratic bottom friction scheme lead to a weaker tidal effect than the one in $T_{\mathrm{L}}$.
Fig. 8 The trajectories of the artificial drifters plotted with 2.5-day interval in $\mathbf{a} \mathrm{WT}_{\mathrm{L}}$ and $\mathbf{b}$ the linear combination of $W_{\mathrm{L}}$ and $T_{\mathrm{L}}$
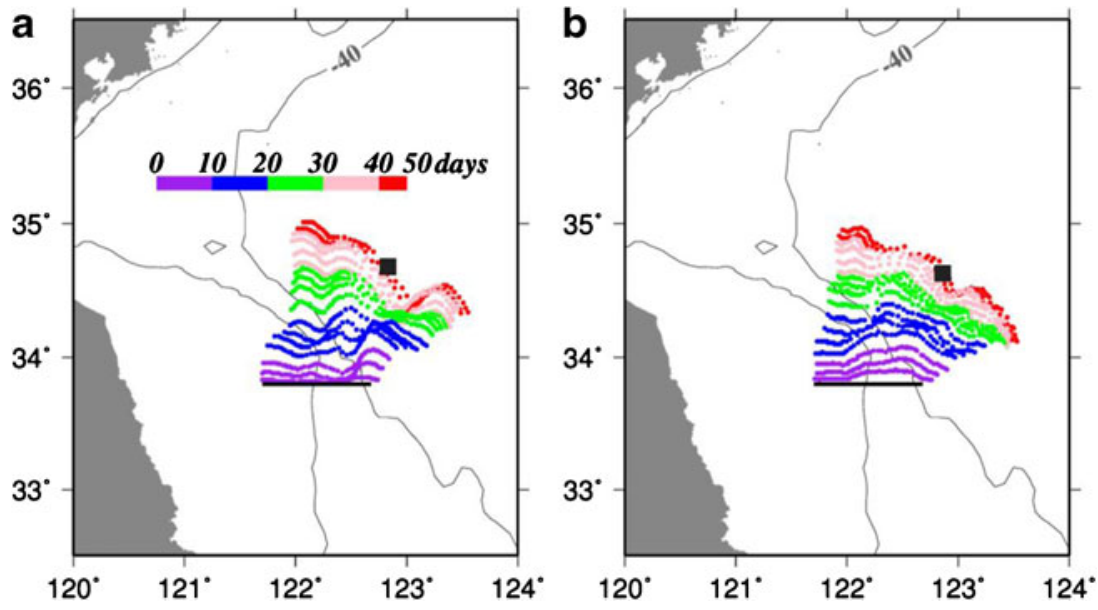
The wind effect, however, shows the opposite behavior: the BMFs in experiment $W_{\mathrm{Q}}$, which uses the quadratic bottom friction scheme, are much smaller than those in $W_{\mathrm{L}}$, resulting in a stronger wind effect.

\section{Effects of synoptic forcing}

The wind forcing employed in previous sections was climatological wind stress from May to June. The realistic wind with a high frequency (synoptic variability) might have an impact on the behavior of the surface drifters. To examine the effects of synoptic winds and to enhance the generality of the results described in the previous section, additional experiments were carried out, in which the JRA-25 6-hourly wind stresses from May to June in 2009 and 2010 were adopted instead of climatology.

For comparison, in the experiment forced by the tidal forcing and the wind stresses from May to June in 2009, the pattern of the modeled drifter trajectories successfully reproduces observation of the ARGOS surface drifters (Fig. 9). Since the wind stress from May to June is feebler than that of observed period, then the final gravity center of these drifters arrives at $35.62^{\circ} \mathrm{N}$, where is slightly south off that of observation. The characters of the ARGOS surface drifters trajectories are simulated well by this experiment, showing

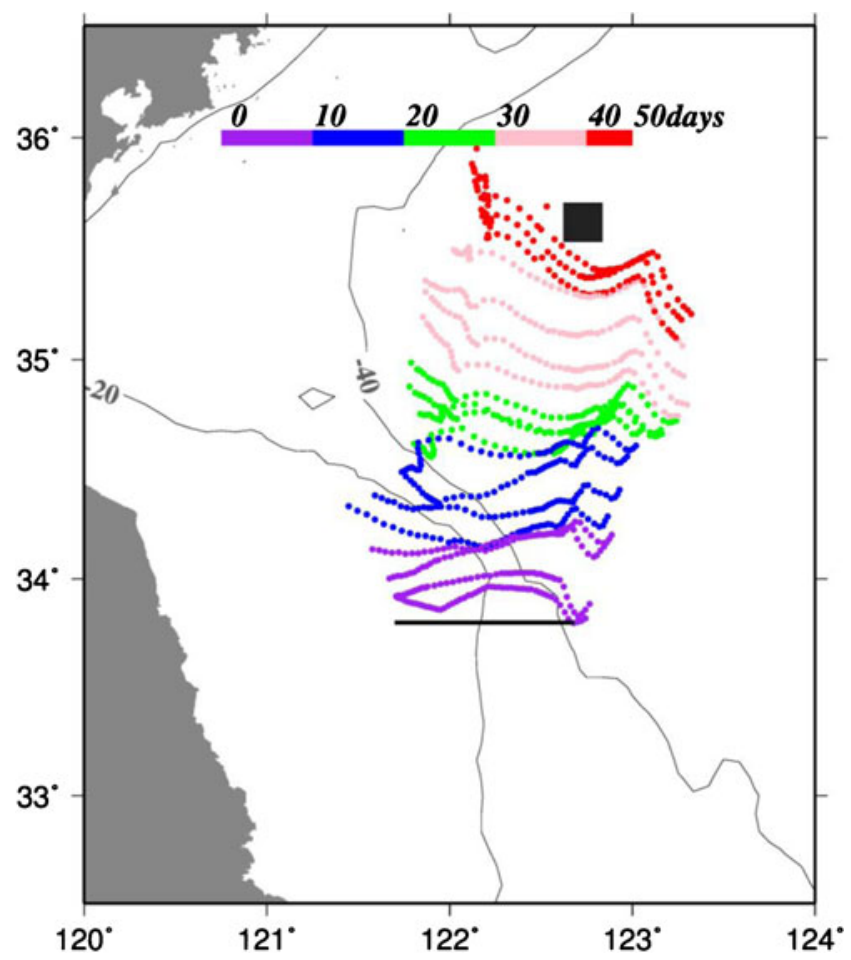

Fig. 9 The trajectories of the artificial drifters plotted with 2.5-day interval in the experiment forced by the tidal forcing and the wind stresses from May to June in 2009 once again that the present model has caught up the realistic features of the regional circulation.

The monthly mean southerly wind in June of $2010(\sim 1$. $09 \mathrm{~m} / \mathrm{s}$ ) is observably weak, even compared to the climatological one $(\sim 1.34 \mathrm{~m} / \mathrm{s})$. The wind effects on Lagrangian trajectories would be minimal in 2010. The experiments forced by wind stress of 2010 should be representative, thus only which are used to check the effects of synoptic winds because of paper length. The prefix $R$ is used to indicate the use of realistic wind forcing in the experiments.

The patterns of the Lagrangian trajectories are essentially the same as those in the climatological experiments. In $\mathrm{RT}_{\mathrm{Q}}$ (Fig. 10a), the modeled drifters released at the northeastern flank of the Yangtze Bank flow northeastward with a mean meridional displacement of $+61.74 \mathrm{~km}$ (Table 2). In this case, the northeastward movement of artificial drifters is suppressed due to the weaker southerly monsoon in summer season of 2010. In the linear combination of $R_{\mathrm{Q}}$ (only forced by realistic wind) and $T_{\mathrm{Q}}$ (only forced by tidal forcing) the mean meridional displacement is $+16.22 \mathrm{~km}$ (Fig. 10b). So, even with the realistic weak wind forcing of 2010, the influence of the Eulerian tidal residual currents on the Lagrangian trajectories is still weaker than the wind effect.

$\mathrm{RT}_{\mathrm{L}}$, which uses the linear bottom friction scheme, reproduces the results $\mathrm{RT}_{\mathrm{Q}}$ (Fig. 10c) with a mean meridional displacement of $+66.41 \mathrm{~km}$. The result of a simple linear combination of $T_{\mathrm{L}}$ and $R_{\mathrm{L}}$ (Fig. 10d) is almost the same as the simulation of $\mathrm{RT}_{\mathrm{L}}$, giving a mean meridional displacement of $+62.38 \mathrm{~km}$ (Table 2). In conformity with the climatological cases, the nonlinearity of the bottom friction leads to a weaker influence of the Eulerian tidal residual currents on the Lagrangian trajectories in the southwestern Yellow Sea.

In a normal year, the southerly wind from May to June is stronger than that of 2010. Thus, the wind effect is expected to be much stronger and the effect of the Eulerian tidal residual current on Lagrangian trajectories may be relatively minor in any summer. Therefore, the experiments using the realistic wind stress of 2010 might indicate the minimum size of the wind effect.

\section{Summary and concluding remarks}

In this study, a high-resolution circulation model based on POM was used to compare the influences of the tidal residual currents and wind-driven currents on Lagrangian trajectories during summer time in the southwestern Yellow Sea. The four kinds of tides $\left(\mathrm{M}_{2}, \mathrm{~S}_{2}, \mathrm{~K}_{1}\right.$, and $\left.\mathrm{O}_{1}\right)$ and climatological wind stress forced the model from May to June. The simulated tidal harmonic constants agreed well with existing studies and observations. The numerical experiments also successfully reproduced the patterns of Eulerian residual 
Fig. 10 The trajectories of the artificial drifters plotted with 2.5-day interval $\mathbf{a}$ in $\mathrm{RT}_{\mathrm{Q}}$, $\mathbf{b}$ the linear combination of $R_{\mathrm{Q}}$ and $T_{\mathrm{Q}}, \mathbf{c}$ in $\mathrm{RT}_{\mathrm{L}}$, and $\mathbf{d}$ the linear combination of $R_{\mathrm{L}}$ and $T_{\mathrm{L}}$
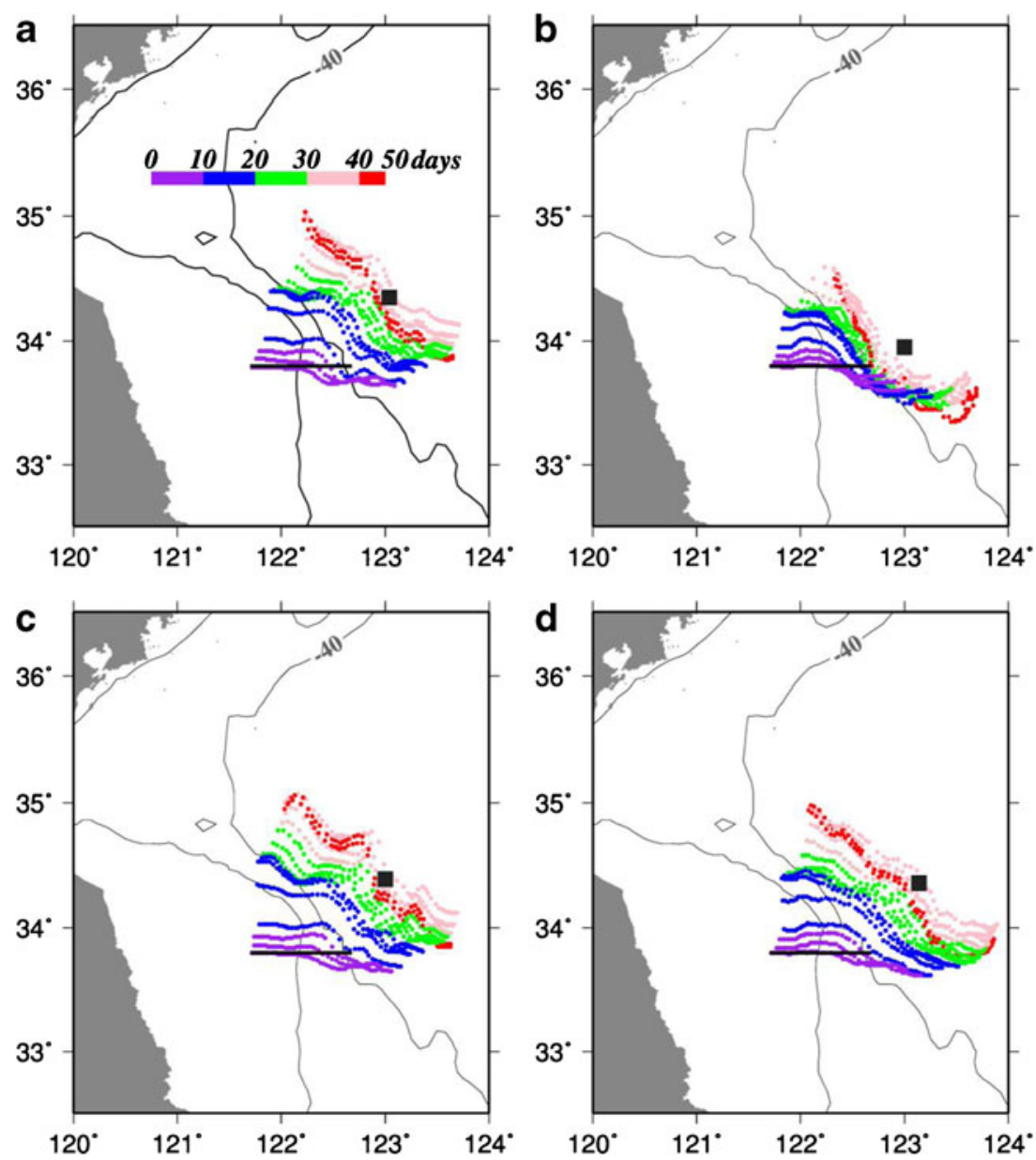

currents in this region that have been shown in previous studies.

Our simulation results showed that the Lagrangian trajectories in the southwestern Yellow Sea are dominated by wind driven currents. The influence of the Eulerian tidal residual currents on Lagrangian trajectories is weaker than that of the southerly wind in summer time. Further experiments indicated that, in the southwestern Yellow Sea, the quadratic nature of the bottom friction led to strong steering effects on the regional circulation in summer, and caused the weaker influence of the Eulerian tidal residual currents on Lagrangian trajectories. This study also demonstrated that Lagrangian trajectories did not follow the Eulerian residual velocity fields in shallow coastal regions. Additional experiments, which used the realistic wind stresses exhibiting high frequency variability from May to June in some particular years, were consistent with the results described above.

In addition to the wind and tidal currents, recent studies suggested that wave effects improved the accuracy of modeled surface currents (Perrie et al. 2003; Tang et al. 2007; Röhrs et al. 2012). This factor probably brings more complex but realistic behaviors of Lagrangian drifters. The consideration of the wave effects on Lagrangian trajectories may be an important future work.

Table 2 The final mean idional displacement of the artificial drifters in the realistic cases

\begin{tabular}{llr}
\hline Experiment & Forcing & $\begin{array}{c}\text { Bottom friction } \\
\text { Final mean meridional } \\
\text { displacement }(\mathrm{km})\end{array}$ \\
$\begin{array}{l}\mathrm{RT}_{\mathrm{Q}} \\
\text { Linear combination of } R_{\mathrm{Q}} \text { and } T_{\mathrm{Q}}\end{array}$ & Both tidal and realistic wind in 2010 & Quadratic \\
$\mathrm{RT}_{\mathrm{L}}$ & Both tidal and realistic wind in 2010 & Linear \\
Linear combination of $R_{\mathrm{L}}$ and $T_{\mathrm{L}}$ & & +16.22 \\
\hline
\end{tabular}


Acknowledgments This work is supported by the MEXT/JSPS Grant-in-Aid for Young Scientists (A) program. The authors thank the Asia-Pacific Data Research Center for providing the Hydrobase2 climatological monthly mean temperature data. The authors also thank Y. Li for kindly providing the original figure of surface ARGOS drifter trajectories. The authors would like to thank the associate editor, Dr. Hidenori Aiki, and the three anonymous reviewers for their valuable comments to improve this paper.

Open Access This article is distributed under the terms of the Creative Commons Attribution License which permits any use, distribution, and reproduction in any medium, provided the original author(s) and the source are credited.

\section{References}

Abbott MR (1960) Boundary layer effects in estuaries. J Mar Res 18:83-100

An HS (1977) A numerical experiment of the M2 tide in the Yellow Sea. J Oceanogr Soc Japan 33:103-110

Bao X, Yan J, Sun W (2000) A three-dimensional tidal model in boundary-fitted curvilinear grids. J. Estuarine Coast Shelf Sci 50:775-788

Beardsley RC, Limeburner R, Kim K, Candela J (1992) Lagrangian flow observations in the East China, Yellow and Japan Seas. Mer 30:297-314

Breton M, Salomon JC (1995) A 2D long-term advection-dispersion model for the Channel and Southern North Sea Part A: Validation through comparison with artificial radionuclides. J Mar Syst 6:495-513

Chen C, Beardsley RC (1995) A numerical study of stratified tidal rectification over finite-amplitude banks, I, Symmetric banks. J Phys Oceanogr 25:2090-2110

Chen C, Beardsley RC, Limeburner R (1995) A numerical study of stratified tidal rectification over finite-amplitude banks, II, Georges Bank. J Phys Oceanogr 25:2111-2128

Choi BH (1980) A tidal model of the Yellow Sea and the eastern China Sea. KORDI Report 80-02, 72 pp

Choi BH (1984) A three-dimensional model of the East China Sea. In Ocean Hydrodynamics of the Japan and East China Seas, ed. by T. Ichiye, Elsevier, Amsterdam, p. 209-224

Choi BH (1990) A fine-grid three-dimensional M2 tidal model of the East China Sea. p. 167-185. In Modeling Marine Systems, ed. by A. M. Davies

Choi BH, Kim KO, Eum HM (2002) Digital bathymetric and topographic data for neighboring seas of Korea. J. Korean Soc. Coastal Ocean Eng 14:41-50 (in Korean with English abstract)

Delhez EJM (1996) On the residual advection of passive constituents. J Mar Syst 8:147-169

Fang G (1986) Tide and tidal current charts for the marginal seas adjacent to China. C J Oceanogr Limnol 4:1-16

Fang G, Wang Y, Wei Z, Choi BH, Wang X, Wang J (2004) Empirical cotidal charts of the Bohai, Yellow, and East China Seas from 10 years of TOPEX/Poseidon altimetry. J Geophys Res 109: C11006. doi:10.1029/2004JC002484

Feng S (1990) On the Lagrangian residual velocity and the mass transport in a multi-frequency oscillatory system. In: Cheng RT (ed) Physics of Shallow Estuarine and Bays, Lecture Notes on Coastal and Estuarine Studies, vol 20. Springer-Verlag, Berlin, pp 18-34

Fischer HB, List EI, Koh R, Imberger I, Brooks NH (1979) Mixing in inland and coastal waters. Academic Press, San Diego, New York, $\mathrm{p} 483$

Gary E, Bennett A, Foreman M (1994) TOPEX/Poseidon tides estimated using a global inverse model. J. Geophys. Res 99 24:821-24 852
Guo X, Yanagi T (1998) Three-dimensional structure of tidal current in the East China Sea and the Yellow Sea. J Oceanogr 54:651-668

Haney RL (1991) On the pressure gradient force over steep topography in sigma-coordinate ocean models. J Phys Oceanogr 21:610-619

Hirose N (2011) Inverse estimation of empirical parameters used in a regional ocean circulation model. J Oceanogr. doi:10.1007/ s10872-011-0041-4

Hu D, Cui M, Li Y, Qu T (1991) On the Yellow Sea Cold Water Massrelated circulation. Yellow Sea Res 4:79-88

Hu DX (1994) Some striking features of circulation in Huanghai Sea and East China Sea. In: Zhou D et al (eds) Oceanology of China Seas, vol 1. Kluwer Academic Publishers, Dordrecht, pp 27-38

$\mathrm{Hu} \mathrm{C}, \mathrm{He}$ MX (2008) Origin and Offshore Extent of Floating Algae in Olympic Sailing Area. Eos Trans AGU 89(33):302-303. doi:10.1029/2008EO330002

$\mathrm{Hu}$ C, Li D, Chen C, Ge J, Muller-Karger FE et al (2010) On the recurrent Ulva prolifera blooms in the Yellow Sea and East China Sea. J Geophys Res 115:C05017. doi:10.1029/2009JC005561

Ianniello JP (1977) Tidally induced residual currents in estuaries of constant breadth and depth. J Mar Res 35:755-786

Jiang W, Feng S (2011) Analytical solution for the tidally induced Lagrangian residual current in a narrow bay. Ocean Dyn 61:543-558

Kang SK, Lee SR, Lei HJ (1998) Fine grid tidal modeling of the Yellow sea and east china seas. Cont Shelf Res 18(7):739-772

Kang SK, Foreman MGG, Lie HJ, Lee JH, Cherniawsky J, Yum KD (2002) Two-layer tidal modeling of the Yellow and East China seas with application to seasonal variability of the M2 tide. J Geophys Res 107(C3):3020. doi:10.1029/2001JC000838

Larsen LH, Cannon GA, Choi BH (1985) East China Sea tide currents. Cont. Shelf Res 4:77-103

Lee SH, Beardsley RC (1999) Influence of stratification on residual tidal currents in the Yellow Sea. J. Geophys. Res 104, 15,679-15, 701 doi:10.1029/1999JC900108.

Li Y (2010) Structure and dynamics of the subtidal circulation in the Southwestern Yellow Sea (in Chinese with English abstract). Doctoral Thesis, IOCAS, pp 33-38

Lie HJ (1986) Summertime hydrographic features in the southeastern Hwanghae. Prog Oceanogr 17:229-242. doi:10.1016/00796611(86)90046-7

Liu Z (2006) Current observations in summers in the southern Yellow Sea. Postdoctoral Report, IOCAS, pp40-43

Longuet-Higgins MS (1969) On the transport of mass by time-varying ocean currents. Deep-Sea Res 16:431-447

Moon JH, Hirose N, Yoon JH (2009) Comparison of wind-tidal contributions to seasonal circulation of the Yellow Sea. J Geophys Res 114:C08016. doi:10.1029/2009JC005314

Naimie CE, Blain CA, Lynch DR (2001) Seasonal mean circulation in the Yellow Sea: a model-generated climatology. Cont Shelf Res 21:667-695

Nishida H (1980) Improved tidal charts for the western part of the North Pacific Ocean. Rep Hydro Res 15:55-70

Ogura S (1933) The tides in the sea adjacent to Japan. Bull Hydro Dept IJN 7:1-189

Perrie W, Tang C, Hu Y, De Tracy BM (2003) The impact of waves on surface currents. J Phys Oceanogr 33:2126-2140

Qiao F, Ma D, Zhu M, Li R, Zang J, Yu H (2008) Characteristics and scientific response of the 2008 Enteromorpha prolifera bloom in the Yellow Sea (in Chinese). Adv Mar Sci 26(3):409-410

Röhrs J, Christensen K, Hole L, Broström G, Drivdal M, Sundby S (2012) Observation based evaluation of surface wave effects on currents and trajectory forecasts. To appear in Ocean Dyn 14 pp, doi: 10.1007/s10236-012-0576-y

Shen Y (1980) Numerical computation of tides in the East China Sea (in Chinese with English abstract). J Shandong Coll Oceanol 10:26-35 
Takahashi S, Yanagi T (1995) A numerical study on the formation of circulations in the Yellow Sea during summer. La Mer 33:135147

Tang Y, Zou E, Lie H et al (2000) Some features of circulation in the southern Huanghai Sea. Acta Oceanol Sin 22(1):1-16

Tang CL, Perrie W, Jenkins AD, De Traccy BM, Hu Y, Toulany B (2007) Observation and modeling of surface currents on the Grand Banks: a study of the wave effects on surface currents. J Geophys Res 112:C10025. doi:10.1029/2006JC004028

Wan Z, Qiao F, Yuan Y (1998) Three-dimensional numerical modelling of tidal waves in the Bohai, Yellow and East China Seas. Oceanol Limnol Sin 29(6):611-616

Wei H, Hainbucher D, Pohlmann T, Feng S, Suendermann J (2004) Tidal-induced Lagrangian and Eulerian mean circulation in the Bohai Sea. J Mar Syst 44:141-151

Xia C, Qiao F, Yang Y, Ma J, Yuan Y (2006) Three-dimensional structure of the summer circulation in the Yellow Sea from a wave-tide circulation coupled model. J Geophys Res 111: C11S03. doi:10.1029/2005JC003218

Xu DF, Yuan YC, Liu Y (2002) The baroclinic current structure of Yellow Sea Cold Mass. Science of China. Ser D 46(2):117-126
Yanagi T, Takahashi S (1993) Seasonal variation of circulations in the East China Sea and the Yellow Sea. J Oceanogr 49:503-520

Yanagi T, Inoue K (1994) Tide and tidal current in the Yellow/East China Seas. La mer 32:153-165

Yanagi T, Morimoto A, Ichikawa K (1997) Co-tidal and corange charts for the East China Sea and the Yellow Sea derived from satellite altimetric data. J Oceanogr 53:303-310

Ye A, Mei L (1995) Numerical modeling of tidal waves in the Bohai Sea, the Huanghai Sea and the East China Sea (in Chinese with English abstract). Oceanol Limnol Sin 26:63-70

Yuan D, Zhu J, Li C, Hu D (2008) Cross-shelf circulation in the Yellow and East China Seas indicated by MODIS satellite observations. J Mar Syst 70(1-2):134-149

Zhang H, Zhu JR, Wu H (2005) Numerical simulation of eight main tidal constituents in the East China Sea, Yellow Sea and Bohai Sea. Journal of East China Normal University (Natural Science Ed.) (3):71-77 (in Chinese with English Abstract.)

Zhao B, Fang G, Cao D (1993) Numerical modeling on the tides and tidal currents in the Eastern China Sea. Yellow Sea Res 5:41-61

Zhao B, Fang G, Chao D (1994) Numerical simulations of the tide and tidal current in the Bohai Sea, the Yellow Sea and the East China Sea (in Chinese). Acta Oceanol Sin 16:1-10 